\title{
Optimizing the Thermal Resistance of Concrete Using The Palm Tree Fronds
} Fibers

\author{
Mohammad Hany Yassin \\ m.yassin@ack.edu.kw \\ Australian College of Kuwait, Kuwait, Kuwait \\ Rana Lakys \\ r.lakys@ack.edu.kw \\ Australian College of Kuwait, Kuwait, Kuwait \\ Taha Ahmed \\ t.ahmed@ack.edu.kw \\ Australian College of Kuwait, Kuwait, Kuwait \\ Shafaq Al-Refaei \\ 1415432@go.ack.edu.kw \\ Australian College of Kuwait, Kuwait, Kuwait \\ Bader Al-Sayed Omar \\ 1211087@go.ack.edu.kw \\ Australian College of Kuwait, Kuwait, Kuwait \\ Rose Shaker Altaher \\ 1313084@go.ack.edu.kw \\ Australian College of Kuwait, Kuwait, Kuwait
}

\begin{abstract}
In the past few years, the issue of global warming has become increasingly visible. Record high as well as record low temperatures are being broken worldwide. Snow is melting in the poles and less sunrays are being reflected causing more temperature to be absorbed by Earth. One of the main reasons of global warming is burning the fossil fuels for producing electrical energy. One of the household items that consumes a lot of electricity is the air conditioner. In the U.S. alone, it is estimated that every airconditioned house produces two tons of carbon dioxide every year. It is believed that if better insulation systems are used in our houses, especially in the GCC area, the use of air conditioners can be optimized to consume less electricity. The main aim of this project is to come up with an environmentally friendly building insulation system that reduces the electrical consumption used in air conditioners in our houses. PTF was prepared and used as a natural free resource that is available locally in the GCC. Several mixes with different PTF ratios have been prepared and tested for thermal insulation and structural integrity. The results indicate a significant improvement in the $\mathrm{R}$ value of concrete. This additive also affected the compressive strength of concrete. It was found that replacing of fine aggregate with less than $1 \%$ of PTF will increase the $\mathrm{R}$ value of concrete without affecting the strength capacity significantly.
\end{abstract}

Keywords: PTF; NFRC; Envelop design; Concrete mix; Insulation; Energy efficient design

\section{INTRODUCTION}

In the past few years, the issue of global warming has become increasingly visible all over the world. Record high as well as record low temperatures are being broken worldwide. Snow is melting in the poles and less sunrays are being reflected causing 
more temperature to be absorbed by Earth. One of the main reasons of global warming is burning the fossil fuels for producing electrical energy. One of the household items that consumes a lot of electricity is the air conditioner. In the U.S. alone, it is estimated that every air-conditioned house produces two tons of carbon dioxide every year. As it gets warmer, our home air conditioners work for more hours and consume more electricity, which further increases the global warming problem. An optimal building envelop design which employ the usage of insulating materials with high $\mathrm{R}$ value, is the most powerful tool for the designer and the constructor to achieve high energy efficiency in buildings (Papadopoulos et al., 2002). It is believed that if better insulation systems are used in our houses, especially in the Gulf Cooperation Council (GCC) area, the use of air conditioners can be optimized to consume less electricity. The traditional envelop design involves the usage of different insulation techniques and materials that has direct contribution to the global warming and harm the environment. This effect is present during the manufacturing of the insulation material (FPS Health, Food Chain Safety \& Environment, 2016) and (U.S. Department of the Interior, 2019) or at the end of the insulation useful lifetime (Dovjak et al., 2017). Consequently, there exists a strong tendency towards preferring "natural" constructional products to the synthetic ones (Dovjak et al., 2017). In the case of thermal insulations. Life Cycle Assessment (LCA) shall be enabled to broaden the meaning of the term "environmentally friendly" (Silvestre et al., 2011). The main aim of this project is to come up with an environmentally friendly building insulation system that reduces the electrical consumption used in air conditioners in our houses. Thermal insulation in concrete building plays an important role in the environment sustainability especially for energy (Shahedan et al., 2017). The use of Natural Fiber Reinforced Concrete (NFRC) walls can result in considerable reduction on the demand on electrical energy for cooling purposes (Al-Jabri et al., 2005). Solar radiation is absorbed by conventional concrete, which stores the heat and releases it later, that can either be during the daytime or night-time (Jhatial et al., 2018). The addition of the fibers in concrete mix will reduces the thermal conductivity (Benmansour et al., 2014) and improve the mechanical properties of concrete such as the tensile and bending strength as well as the ductility cracks propagation resistance [10]. Thus, utilization of Palm Tree Fronds (PTF) as filler in concrete seems to be a very promising option which allows to be applied as thermal insulation materials in buildings (Benmansour et al., 2014). PTF was selected in to be investigated in this research because it is natural free resource that is available locally in the GCC countries.

\section{MATERIALS and METHODS}

The objective of this research is to enhance the thermal properties of the concrete in order to replace the locally widely available PTF eco-friendly material with the currently used eco-unfriendly insulation substances. Therefore, the focus in this research was mainly on the changes in the R-value of concrete with respect to the added amount of PTF to the concrete mix. However, the effect of this addition on the strength of concrete was also evaluated through structural tests. The results are used as a proof of concept. Nevertheless, a more comprehensive testing program that considers several elements in the mix and their effects on the quality of the concrete product shall be performed. Currently at the civil engineering lab in ACK, several grades of concrete with different 
testing techniques are being developed and investigated. The aim of the program is to investigate the effect of adding PTF on the mechanical properties, workability and durability of concrete. In this paper the results of thermal conductivity and compressive strength of concrete cube samples are reported.

\subsection{Collection and preparation:}

The PTF was collected for free from a local date farm. After drying under sun, the leaves were grinded in a special mill. The grinding was performed in two cycles in order to obtain a powder-like consistency. The consistency of the powder from the first and second cycle is illustrated in Figure 1.

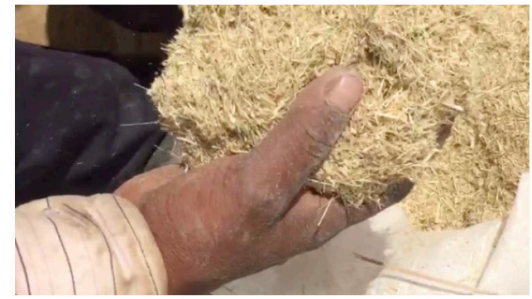

(a)

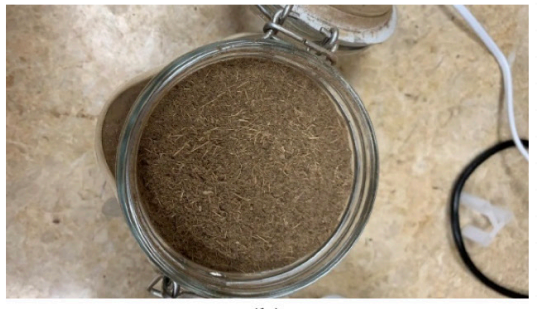

(b)

Figure 1: PTF after grinding (a) first cycle (b) second cycle

\subsection{Sieve analysis:}

The effect of the size of the PTF powder particles was examined. The powder from the mill came in sizes range between 0.07 and $7 \mathrm{~mm}$. Therefore, two practices were followed in this study. In the first practice, a sieve analysis was conducted on the powder and only powder passed through certain sieve was used in the mix. Where in the other practice the raw powder was used directly without any filtration. Using the data from the sieve analysis, illustrated in Table 1 and Figure 2, it was determined that anything passing sieve No. 50 (particle size $0.355 \mathrm{~mm}$ ) would be used as PTF powder for the concrete mix. Overall, PTF fiber to PTF Powder had a yield of $17.8 \%$. This meant, theoretically, that $2.67 \mathrm{~kg}$ of PTF Powder could be extracted from an original PTF powder amount of $15 \mathrm{~kg}$. Figure 3, illustrates the amount and consistency of PTF powder from sieving $1.7 \mathrm{~kg}$ of PTF ground fiber. This method resulted in very small amount of PTF but has slightly improved the results of the strength tests.

Table 1: Sieve analysis results for the ground PTF

\begin{tabular}{ccccccc}
\hline $\begin{array}{c}\text { Sieve } \\
\text { Number }\end{array}$ & $\begin{array}{c}\text { Openings } \\
(\mathbf{m m})\end{array}$ & $\begin{array}{c}\text { Mass of Empty } \\
\text { Sieve }(\mathbf{g})\end{array}$ & $\begin{array}{c}\text { Mass of Sieve \& } \\
\text { PTF }(\mathbf{g})\end{array}$ & $\begin{array}{c}\text { Mass of PTF } \\
(\mathbf{g})\end{array}$ & $\begin{array}{c}\text { Cumulative Mass of } \\
\text { PTF }(\mathbf{g})\end{array}$ & Percent (\%) \\
\hline 6 & 6.300 & 758.6 & 798.3 & 39.7 & 39.7 & 72.35 \\
\hline 4 & 4.750 & 749.1 & 749.1 & 0.0 & 39.7 & 72.35 \\
\hline 8 & 2.360 & 443.3 & 443.8 & 0.5 & 40.2 & 72.01 \\
\hline 16 & 1.180 & 633.1 & 637.3 & 4.2 & 44.4 & 69.08 \\
\hline 30 & 0.600 & 600.4 & 617.8 & 17.4 & 61.8 & 56.96 \\
\hline 40 & 0.425 & 334.1 & 352.9 & 18.8 & 80.6 & 43.87 \\
\hline 50 & 0.355 & 534.8 & 552.7 & 17.9 & 98.5 & 31.41 \\
\hline 100 & 0.150 & 507.0 & 531.0 & 24.0 & 122.5 & 14.69 \\
\hline 200 & 0.075 & 488.2 & 499.0 & 10.8 & 133.3 & 7.17 \\
\hline Pan & - & 471.0 & 481.3 & 10.3 & 143.6 & 0.00 \\
\hline
\end{tabular}




\subsection{Water absorption test}

Three samples of the powdered PTF were tested for the water absorption as per the ASTM C128-15 standard(C09 Committee, 2015). The samples were dried in the oven for 24 hours prior to the test. The weight of the dried powder was measured using an electronic. The substance was then soaked in water for an hour to reach its saturation level. The saturated PTF mass was then weighed. The difference between the two masses was calculated. The test was carried out for sieved and raw PTF. Lab results indicate high water absorption ratio between 95\% -107\%. Similar findings were reported in other studies (Saba et al., 2016) \& (Ferrández-García et al., 2018). The high-water absorption and low mechanical properties of these natural fibers limit some of their applications (Saba et al., 2016). The large WA will reduce the amount of water in the mix affects both workability and ultimate strength of concrete. In order to maintain the $\mathrm{W} / \mathrm{C}$ ratio in the concrete mix, the amount of water absorbed by the PTF was calculated and considered during the preparation of the concrete samples. The calculated amount of PTF powder for each set of samples was socked for 24 hours in the equivalent to weight absorbed of water prior to the mixing to avoid adding excessive water to the mix.

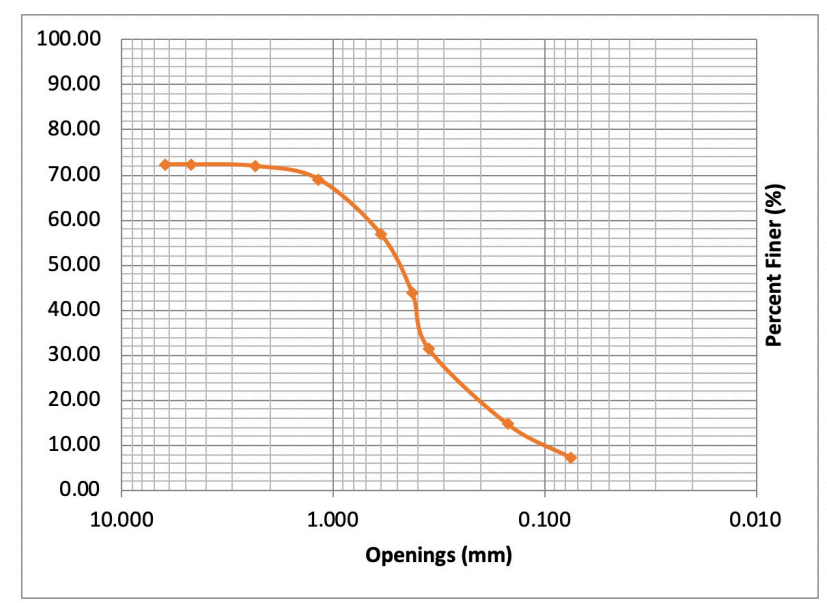

Figure 2: Sieve analysis results for the ground PTF

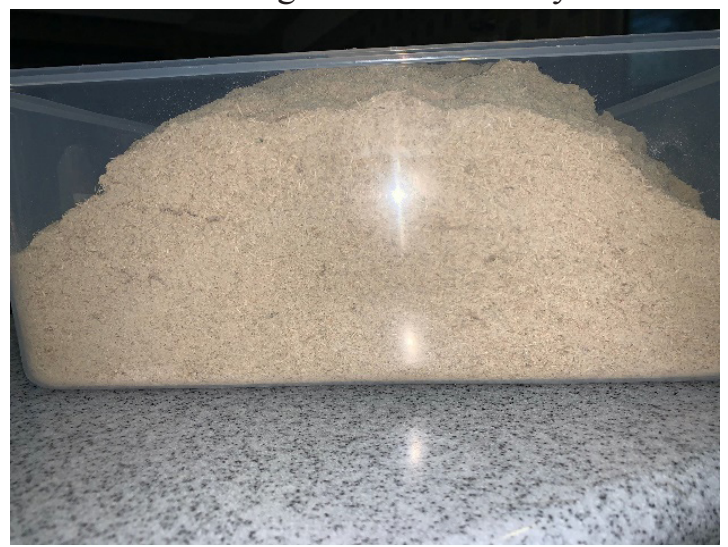

(a)

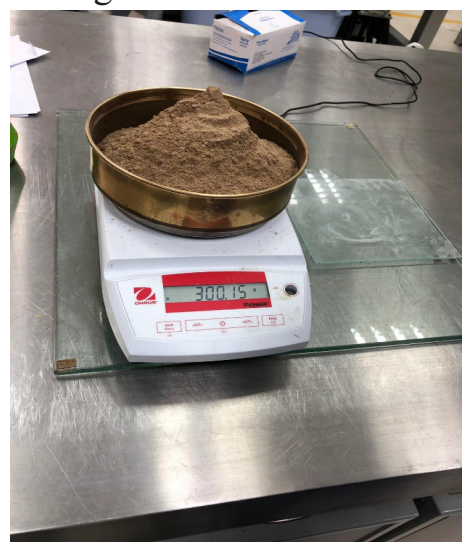

(b)

Figure 3: (a) PTF powder, (b) 300 gr of PTF powder extracted from $1.7 \mathrm{~kg}$ of PTF fiber 


\subsection{Mixing, casting and curing}

The dry ingredients were mixed first then water was added slowly with the socked wet PTF. After mixing, concrete workability was checked with the mean of slump test as presented in Figure 4. Concrete was casted into $100 \times 100 \times 100 \mathrm{~mm}$ cube as well as $20 \times 40$ cylindrical and $100 \times 100 \times 600$ beam samples. The number of samples for each test is shown in Table 2. Special 3D printed plastic molds were prepared for the thermal conductivity test as presented in Figure 4 (a). The samples were cured in water under room temperature for 28 days prior to testing.

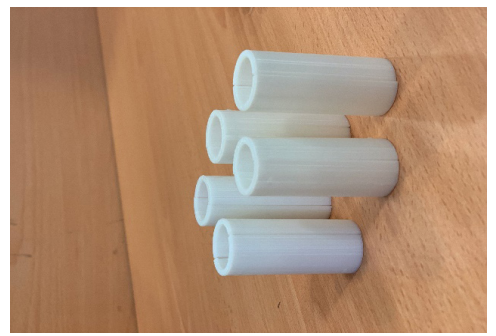

(a)

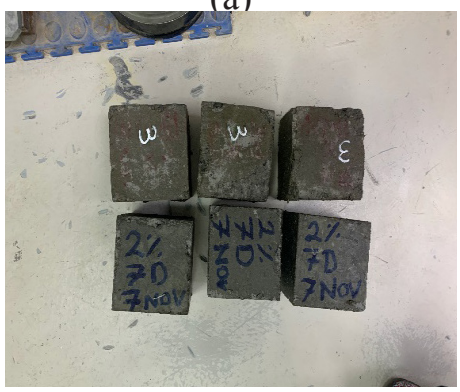

(c)

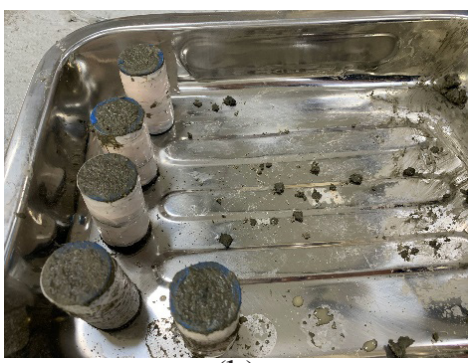

(b)

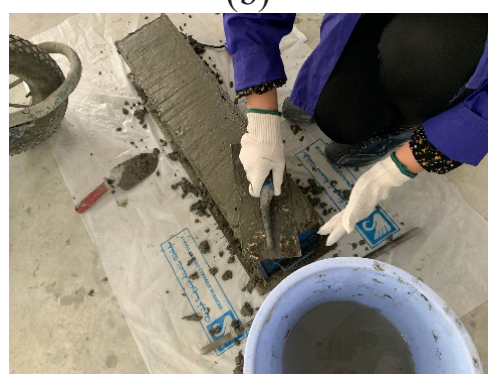

(d)

Figure 4: (a) 3D printed plastic concrete moulds for thermal conductivity (b) casted cylindrical samples (c) casted cube samples (d) casted beam sample

Table 2: Testing Matrix

\begin{tabular}{|c|c|c|c|}
\hline PTF \% & $\begin{array}{c}\text { Cube samples } \\
100 \times 100 \times 100(\mathrm{~mm}) \\
\text { Test: Compressive } @ 28\end{array}$ & $\begin{array}{c}\text { Cylindrical samples } \\
\qquad \mathbf{2 0 \times 4 0}(\mathrm{mm}) \\
\text { Test: } \text { Thermal Conductivity }\end{array}$ & $\begin{array}{c}\text { Beam samples } \\
100 \times 100 \times 600(\mathrm{~mm}) \\
\text { Test: Flexural Strength }\end{array}$ \\
\hline 0 & 3 & 4 & 1 \\
\hline 1 & 3 & 4 & 1 \\
\hline 1.25 & 3 & 4 & 1 \\
\hline 2 & 3 & 4 & 1 \\
\hline 2.5 & 3 & 4 & 1 \\
\hline 3 & 3 & 4 & 1 \\
\hline 4 & 3 & 4 & 1 \\
\hline 5 & 3 & 4 & 1 \\
\hline
\end{tabular}




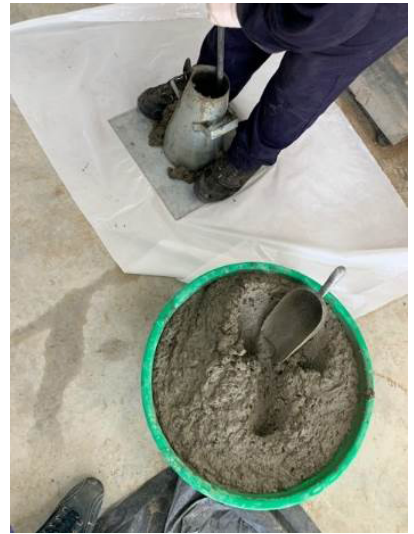

(a)

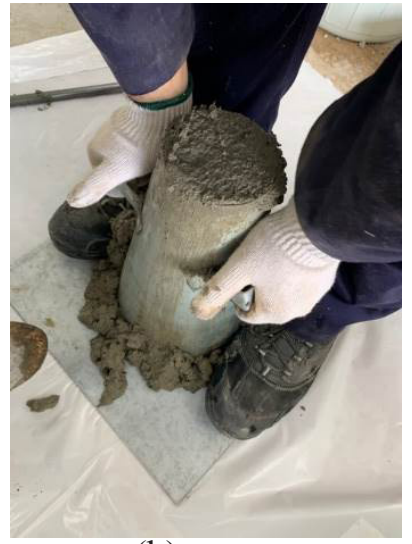

(b)

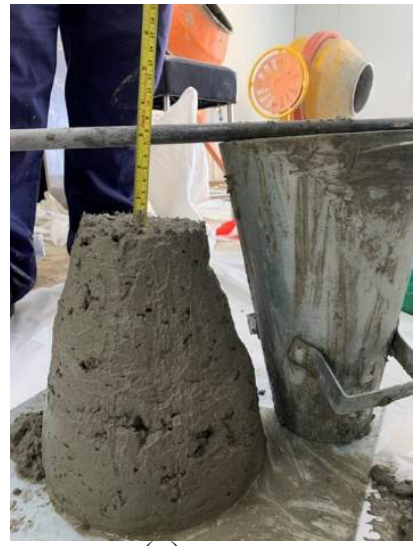

(c)

Figure 5: Workability check of concrete with the slump test

(a) concrete sampling (b) placing the concrete in the cone mold (c) measuring slump

\subsection{Tests and procedures}

Cube samples were tested under compression to check the compressive strength of concrete at age of 28 days. The test was performed at the Civil and Mechanical labs in ACK. The beam samples were tested under pure bending conditions to check the effect of variant percentage of PTF additive on the flexural capacity of concrete. All beam samples have an identical reinforcement as shown in Figure 8.

The cylindrical samples were tested using the G.U.N.T Hamburg WL 420 Heat Conduction testing machine presented in Figure 6. Figure 7 depicts the beam sample dimensions and reinforcement. Samples during and after tests are depicted in Figures 8 and 9.
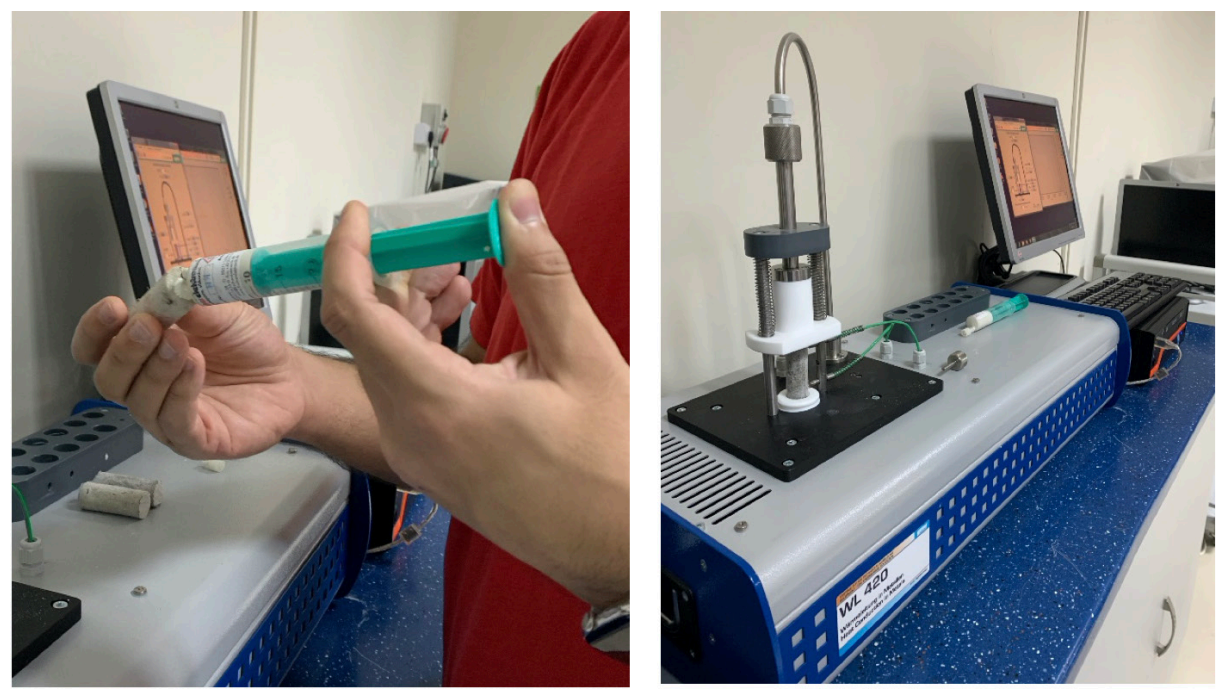

Figure 6: Preparing Concrete Cylinder with Silicone for Conductivity Test (left) and Thermal Conductivity Test on Concrete Cylinder (right) 

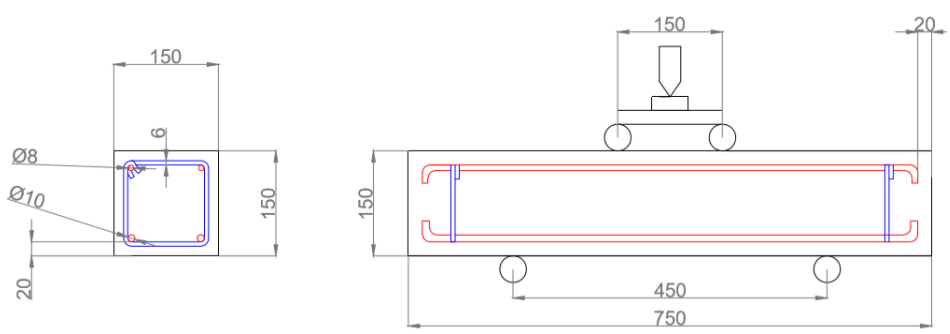

Figure 7: Sketch of concrete beam samples showing section reinforcement, supports span and loading points

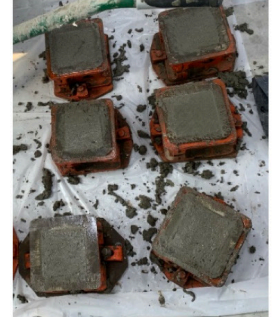

(a)

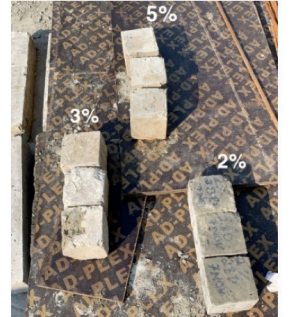

(b)

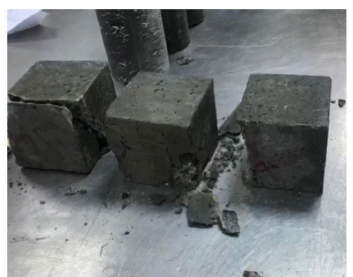

(c)

Figure 8: Concrete cube samples (a) after casting (b) after curing (c) after compressive test
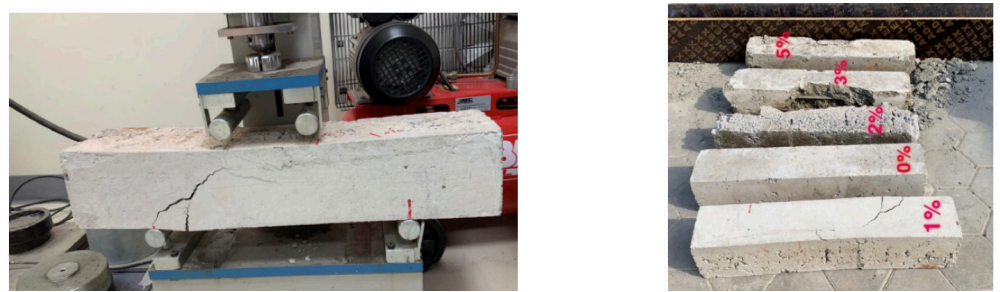

Figure 9: Concrete beam samples during and after test

\section{RESULTS AND DISCUSSION}

The addition of the natural PTF has noticeably improved its thermal resistance capacity as expected. On the other hand, the compressive strength of concrete cubes and the flexural capacity of the beam samples has shown an inversely proportional reduction with the add percentage of PTF. The results of the thermal conductivity of the concrete has linearly decreased with the increased amount of PTF. This means that thermal resistance of concrete, represented in R-value, is increasing when we add more PTF. However, this thermal resistance enhancement will be on the cost of the structural integrity of the concrete. A summary of averaged results for mechanical and thermal tests is presented in Table 3. The results of the compressive strength are shown in Figure 10 and the results of the measured thermal conductivity with respect to the percentage of PTF in the concrete mix is shown in Figure 11 (a). Figure 11 (b) depicts the increase in the calculated thermal resistance of concrete as a variable of PTF replacement percentage. The thermal conductivity of concrete is normally below $1.9 \mathrm{~W} / \mathrm{k} . \mathrm{m}$ and depends mainly on the density and the water content in concrete (Carman \& Nelson, 1921), (Asadi et al., 2018). The high initial conductivity obtained in this research indicates high percentage 
of minerals and high water content in the concrete after hardening even for the plain concrete specimens. For the concrete with added PTF, although the thermal resistance was enhanced, the conductivity with low percentage of PTF indicates high water content in the concrete even after 28 days of curing. This water content will potentially decrease with time but other alternatives can be followed to avoid this problem. The other noticed result here is the severe degradation in the compressive strength and flexural strength of concrete specimens after $1 \%$ of sand replacement. This is correspondingly can be correlated to the high water content in the concrete which was absorbed by the PTF prior to the mix. The solution for this might be through the chemical treatment of PTF prior to the mix. Machaka and others have reported that treating PTF with NAOH solution prior to the mix will enhance its tensile properties and reduce the water absorption significantly (Machaka et al., 2014). This aspect is being considered in the second phase of this project in ACK.

Table 3: Testing results for several percentages of added PTF powder

\begin{tabular}{ccccc}
\hline PTF\% & $\begin{array}{c}\text { Averaged } \\
\text { Stress } \\
\mathbf{M P a}\end{array}$ & $\begin{array}{c}\text { Flexural } \\
\text { Strength } \\
{[\mathbf{k N}]}\end{array}$ & $\begin{array}{c}\text { Averaged Thermal } \\
\text { Conductivity } \\
\text { (W/k.m) }\end{array}$ & $\begin{array}{c}\text { R-Value } \\
{\left[\mathbf{m}^{2} . \mathbf{K} / \mathbf{W}\right]}\end{array}$ \\
\hline $\mathbf{0}$ & 2923.00 & 96.52 & 3.90 & 0.010 \\
\hline $\mathbf{1}$ & 20.43 & 64.61 & 3.62 & 0.011 \\
\hline $\mathbf{1 . 2 5}$ & 15.58 & 49.89 & 3.50 & 0.011 \\
\hline $\mathbf{2}$ & 5.70 & 5.70 & 1.60 & 0.042 \\
\hline $\mathbf{2 . 5}$ & 4.25 & 3.12 & 0.60 & 0.067 \\
\hline $\mathbf{3}$ & 3.10 & 2.20 & 0.50 & 0.080 \\
\hline $\mathbf{4}$ & 1.42 & 2.48 & 0.40 & 0.100 \\
\hline $\mathbf{5}$ & 0.20 & 3.10 & 0.30 & 0.120 \\
\hline
\end{tabular}

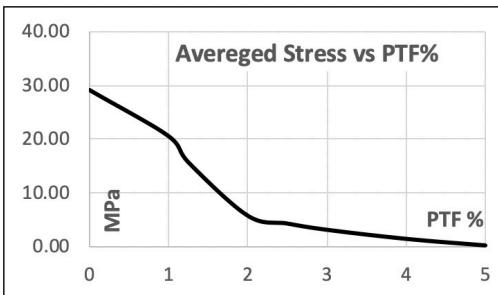

(a)

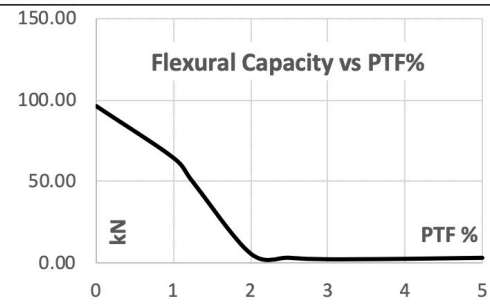

(b)

Figure 10: Concrete strength capacity with respect to the percentage of added PTF (a) compressive strength (b) flexural strength

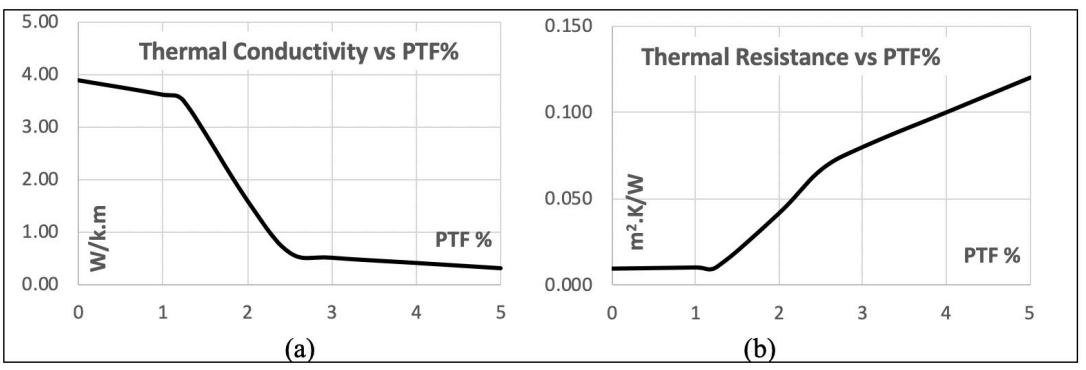

Figure 11: (a) Concrete thermal conductivity with respect to the percentage of added PTF

(b) Corresponding concrete thermal resistance with respect to the percentage of added PTF 


\section{CONCLUSION}

In conclusion, PTF powder additive can potentially enhance the thermal and mechanical properties of concrete better than PTF fibers. However, it has high water absorption properties. The high water absorption influences negatively both the mechanical and thermal resistance of concrete. Care shall be taken in order to chemically treat the PTF prior to mixing with concrete. The chemical treatment with $\mathrm{NaOH}$ can potential improve the tension capacity of PTF and reduces its water absorption. Thermal conductivity has increased significantly due to the replacement of fine aggregate with PTF however this came on the cost of concrete strength. In this study several PTF replacement percentages was tested. A maximum ratio of $1 \%$ was found to be practical. This percentage can be hypothetically increased by treating the PTF to eliminate its water absorption. It is expected that this ratio can be increased sufficiently if the water absorption problem has been controlled by means of chemical pre-treatment of the fibers.

\section{REFERENCES}

Al-Jabri, K. S., Hago, A. W., Al-Nuaimi, A. S., Al-Saidy, A. H. (2005). Concrete blocks for thermal insulation in hot climate. Cement and Concrete Research 35, 1472-1479. https://doi. org/10.1016/j.cemconres.2004.08.018.

Asadi, I., Shafigh, P., Abu Hassan, Z. F. B., Mahyuddin, N. B. (2018). Thermal conductivity of concrete - A review. Journal of Building Engineering, 20, 81-93. https://doi.org/10.1016/j. jobe.2018.07.002.

Benmansour, N., Agoudjil, B., Gherabli, A., Kareche, A. \& Boudenne, A. (2014). Thermal and mechanical performance of natural mortar reinforced with date palm fibers for use as insulating materials in building. Energy and Buildings, 81, 98-104. https://doi.org/10.1016/j. enbuild.2014.05.032

C09 Committee (2015). Test Method for Relative Density (Specific Gravity) and Absorption of Fine Aggregate. ASTM International. https://doi.org/10.1520/C0128-15.

Carman, A. P. \& Nelson, R. A. (1921). Thermal conductivity and diffusivity of concrete / (Bulletin No. 122), University of Illinois Bulletin. University of Illinois, Urbana-Champaign Library.

Dovjak, M., Košir, M., Pajek, L., Iglič, N., Božiček, D. \& Kunič, R. (2017). Environmental Impact of Thermal Insulations: How Do Natural Insulation Products Differ from Synthetic Ones? IOP Conf. Ser.: Earth Environ. Sci. 92, 012009. https://doi.org/10.1088/1755-1315/92/1/012009.

Ferrández-García, C. E., Ferrández-García, A., Ferrández-Villena, M., Hidalgo-Cordero, J., García-Ortuño, T. \& Ferrández-García, M. T. (2018). Physical and mechanical properties of particleboard made from palm tree prunings. Forests 9, 755. https://doi.org/10.3390/f9120755.

FPS Health, Food Chain Safety and Environment (2016). The Environmental Impact of Thermal Insulation Materials [WWW Document]. FPS Public Health. URL https://www.health. belgium.be/en/environmental-impact-thermal-insulation-materials (accessed 11.17.19).

Jhatial, A. A., Goh, W. I., Mohamad, N., Alengaram, U. J. \& Mo, K. H. (2018). Effect of Polypropylene Fibers on the Thermal Conductivity of Lightweight Foamed Concrete, MATEC Web of Conferences, 150, 03008. https://doi.org/10.1051/matecconf/201815003008.

Machaka, M. M., Basha, H. S. \& ElKordi, A. M. (2014). The effect of using fan palm natural fibers on the mechanical, Properties and Durability of Concrete. IJMSE. https://doi.org/10.12720/ ijmse.2.2.76-80. 
Papadopoulos, A. M., Karamanos, A., Avgelis, A. (2002). Environmental Impact of Insulating Materials at The End of Their Useful Lifetime 9.

Saba,N.,Paridah,M.T.,Abdan,K.\&Ibrahim,N.A.(2016).Physical,structuralandthermomechanical properties of oil palm nano filler/kenaf/epoxy hybrid nanocomposites. Materials Chemistry and Physics, 184, 64-71. https://doi.org/10.1016/j.matchemphys.2016.09.026.

Shahedan, N. F., Abdullah, M. M. A. B., Mahmed, N., Kusbiantoro, A., Binhussain, M. \& Zailan, S. N. (2017). Review on thermal insulation performance in various type of concrete. Presented at the advanced materials engineering and Technology V: International Conference on Advanced Material Engineering and Technology 2016. Kaohsiung City, Taiwan, p. 020046. https://doi.org/10.1063/1.4981868.

Silvestre, J. D., De Brito, J. \& Duarte Pinheiro, M. (2011). Life-Cycle Assessment of Thermal Insulation Materials for External Walls of Buildings. https://doi.org/10.13140/ RG.2.1.1756.7768.

U.S. Department of the Interior (2019). Environmental Considerations of Building Insulation National Park Service - Pacific West Region. 